\title{
THE KNOWLEDGE REGARDING HBV INFECTION AMONG NURSING STAFF.
}

\section{Dr Neha Rehalia \\ Dr Vivek Chaudhary*}

ABSTRACT

Background: The knowledge of nursing staff regarding hepatitis B virus (HBV) when their daily activities will be closely related to patients' body fluids, plays vital role in minimizing the risk of acquiring HBV

infection

Objective: We aimed to assess the knowledge regarding HBV infection among nursing staff.

Materials and Methods: A descriptive cross-sectional study was conducted using a structured self-administered questionnaire among the nursing staff in Civil hospital, Shahpur, Kangra (HP).

Results: Most (60\%) of staff nurses had good knowledge followed by (3\%) who had excellent knowledge and few (1\%) staff nurses with average knowledge score regarding universal precautions about hepatitis B. No staff nurse had poor knowledge score. All of the (100\%) staff nurses had desirable attitude regarding universal precautions about hepatitis B.

Conclusion: The staff had good knowledge regarding HBV infection and its preventive aspect.

\section{KEYWORDS :}

\section{INTRODUCTION}

Hepatitis is characterized by the inflammation of liver and in many cases hepatitis $\mathrm{B}$ and $\mathrm{C}$ can lead to permanent liver damage including liver cirrhosis or hepatocellular carcinoma and even death.[1] In South-East Asian Region, there are estimated 80 million hepatitis B virus (HBV) carriers (about 6\% of the total population).[2] India has the intermediate endemicity of hepatitis $B$, with hepatitis B surface antigen prevalence between $2 \%$ and $10 \%$ among the population studied.[3] The number of carriers in India has been estimated to be over 40 million. [3] The true prevalence of hepatitis B in non-tribal populations is $2.4 \%$ tribal populations is $15.9 \%$ as per recent data.[4] Alarmingly two studies specifically, looking at professional donors have noted prevalence of $55.3 \%$ and $87.3 \%$ for hepatitis C. [5,6] It has been estimated that $14.4 \%$ of hospital workers are infected with HBV.[7] Physicians, dentists, nurses, laboratory staff, and chair side assistants are at high-risk of acquiring infection via the contact with blood (and other body fluids) in the course of their work. [8] Among the health care personals', HBV is transmitted by the skin prick with an infected, contaminated needles and syringes or through accidental inoculation of minute quantities of blood during the surgical and dental procedures. It has been seen in the literature that the highest prevalence of HBV exists in dentists.[9] HBV can be prevented by strict adherence to standard microbiological practices and techniques, and routine use of appropriate barrier precautions to prevent skin and mucous membrane exposure when handling blood and other body fluids of all patients in health-care settings and pre-exposure vaccines. Even after many publications about programs and strategies to prevent transmission, HBV infection still remains a major public health issue for mankind.[10]

It has been recommended that prevention is a safeguard against epidemic of viral hepatitis. By knowing facts, having proper awareness, and attitudes the menace of this disease can be prevented to a great extent.[1 1] As health-care workers (HCWs) remain at a high-risk of transmission by skin prick with infected, contaminated needles and syringes or through accidental inoculation of minute quantities of blood during the surgical and dental procedures it is very important for them to follow proper measures of infection control and prevention.

The knowledge regarding hepatitis B and its related safety precautions is essential to minimize the acquired infections in health-care settings among health personnel, especially medical and dental students who are more vulnerable to HBV infection as they remain in direct contact with the infected patients, blood, injections, and surgical instruments during the course of clinical work.[12,13] Noubiap et al. have found a good knowledge of the risk factors for HBV infection and awareness of HBV vaccine among medical students of clinical years in Camroon.[14] Similarly, a study among medical students at Syrian Private University revealed the weakness of general knowledge about hepatitis B among junior medical students compared to those in the fifth year.[15]

The literature search did not reveal any study regarding the assessment of knowledge about hepatitis B among preclinical nursing staff in our area. Therefore, this study sought to assess the knowledge and attitude among nursing students in selected hospitals in Punjab.

\section{SUBJECTS AND METHODS}

This cross-sectional, descriptive, institutional-based study was conducted among 10 nursing staff Civil hospital, Shahpur. The study subjects were fully informed about the design and purpose of the study.

\section{INCLUSION CRITERIA}

- Staff nurses of civil hospital, Shahpur

- Staff nurses who were willing to participate

- Staff nurses who were present at the time of study.

\section{EXCLUSION CRITERIA}

- Staff nurses who were not present during the time of data collection.

- Staff nurses who were not interest in the study.

\section{STATISTICAL ANALYSIS}

Analysis of data was done by using the descriptive and inferential statistics, i.e. mean, mean percentage, standard deviation (SD), Karl Pearson's correlation coefficient and ANOVA, were used to identify the significant relationship of knowledge and attitude regarding universal precautions about hepatitis B among staff nurses. The level of significance chosen was $p<0.05$. Statistical analysis was performed using SPSS v2l.

\section{RESULTS}

Table l shows general characteristics of the study population. According to age majority of staff nurses (80\%) were in the age 
group of 2l-33 year, followed by (20\%) who were in age group of 34-46 years. All of were females. According to qualification, maximum number of staff nurses (80\%) were GNM and (20\%) were B.Sc. (N). Based on professional experience most of the staff nurses $(80 \%)$ were having $>5$ year of experience, followed by (20\%) 1-5 years. Regarding source of information maximum number of (40\%) staff nurses got information through staff development program, $(30 \%)$ from curriculum, $(20 \%)$ from in service education and $(20 \%)$ from mass media.

Knowledge among staff nurses regarding universal precautions about hepatitis B

We observed that most $(51 \%)$ of staff nurses had good knowledge followed by (44\%) who had excellent knowledge and few (5\%) staff nurses with average knowledge score regarding universal precautions about hepatitis B . No staff nurse had poor knowledge score (fig l).

Attitude regarding universal precautions about hepatitis B among the staff nurses

We observed that all of the (100\%) staff nurses had desirable attitude regarding universal precautions about hepatitis B (table 2).

Association of mean knowledge score among staff nurses regarding universal precautions about hepatitis $B$ according to age

Table 3 shows the relationship value between knowledge score and attitude score was 0.224 . It depicts that there was positive relationship between knowledge and attitude of staff nurses regarding universal precautions about hepatitis B.

\section{DISCUSSION}

Hepatitis B is a major health problem globally casting an enormous burden on the health-care system and a major source of patient's misery. They are important causes of hepatocellular carcinoma and are likely to remain a serious health problem resulting in substantial morbidity and mortality for several decades to come. These infections are also an important occupational hazard for HCWs. Generally, it is easy to assume that health workers by virtue of their proximity to the health facility should have adequate knowledge about diseases and other health conditions. Therefore, this study has been carried out with a motive to assess the knowledge and attitude regarding the hepatitis $B$ infection.

The knowledge on the preventive aspect of HBV also showed that the participants had a good knowledge on this matter. As the evidence of HBV transmission to and from health-care workers is very high, vaccination is the most important way to prevent hepatitis B diseases other than following strict hygiene with all invasive procedures and a considerate lifestyle. A majority of the nursing staff demonstrated a good to excellent level of knowledge of hepatitis B infection. This finding is however, at variance with another study done in Karachi (Pakistan) where the respondents demonstrated a very low knowledge of hepatitis $B$ infection.[16] The results were similar but slightly better than another study done on Nigerian HCWs.[17]

The most potential source of cumulating the information regarding HBV among the participants was found to be staff developmental program followed by curriculum, in-service education, and mass media. Similar study done among nursing students of different colleges in Kathmandu also revealed that radio/television followed by poster/booklets, newspaper, teachers, and friends were the sources of information for the participants.[18] The availability of resources and place influence the source of information that prominently affects the knowledge on respective matter. These common tools can also be used to fill any gaps in the knowledge and practice of universal precautions among upcoming physicians and surgeons in our and similar settings.

It is the responsibility of the academicians to ensure that their preclinical students have ample knowledge regarding this transmissible disease before they come in contact with patient's blood, other body fluids, and different medical/surgical intervention in clinical years so that occupational risk can be minimized. The vaccination program against HBV should be conducted to cover all the staff before the start of their work.

\section{CONCLUSION}

Overall, good knowledge and attitude revealed by this study among nursing staff regarding hepatitis B can be utilized effectively to motivate the students for vaccination against HBV and adaptation of different safety precautionary measures to reduce the occupational risk in future.

\section{Table 1. General characteristics}

\begin{tabular}{|l|l|l|}
\hline & n & $\%$ \\
\hline Age (Years) & 87 & 87 \\
$21-33$ & 13 & 13 \\
$34-46$ & 0 & 0 \\
$47-58$ & & \\
\hline Gender & 28 & 28 \\
Male & 72 & 72 \\
Female & & \\
\hline Qualification & 74 & 74 \\
GNM & 26 & 26 \\
BSc (N) & 0 & 0 \\
Post BSc (N) & & \\
\hline Experience (Years) & 52 & 52 \\
$<1$ & 41 & 41 \\
1-5 & 7 & 7 \\
6-10 & 0 & 0 \\
$>10$ & & \\
\hline Working area & 35 & 35 \\
Medical ward & 26 & 26 \\
Surgical ward & 16 & 16 \\
ICU & 18 & 18 \\
Emergency & 5 & 5 \\
Any other & & \\
\hline Source of information & 13 & 13 \\
Mass media & 21 & 21 \\
In-service education & 28 & 28 \\
Curriculum & 38 & 38 \\
Staff development program & & \\
\hline Course completed information & 93 & 93 \\
Private & 7 & 7 \\
Govt & & \\
\hline
\end{tabular}

Table 2. Frequency and percentage distribution level of attitude regarding universal precautions about hepatitis Bamong staff nurses

\begin{tabular}{|l|l|l|l|}
\hline & \multicolumn{4}{|l|}{ Attitude score } \\
\hline Level of attitude (\%) & Score & $\mathrm{n}$ & Percentage \\
\hline Desirable $(\geq 40 \%)$ & $\geq 40 \%$ & 100 & $100 \%$ \\
\hline Undesirable $(<40 \%)$ & $<40 \%$ & - & - \\
\hline
\end{tabular}

Table- 3 Relationship between the knowledge and attitude of staff nurses regarding universal precautions about hepatitis B.

\begin{tabular}{|c|c|c|c|c|}
\hline \multirow{2}{*}{ Relationship } & \multicolumn{4}{|c|}{ Knowledge and Attitude Score } \\
\cline { 2 - 5 } & Maximum score & Mean & SD & r \\
\hline Knowledge & 30 & 18.68 & 4.72 & 0.224 \\
\hline Attitude & 60 & 56.97 & 4.34 & \\
\hline
\end{tabular}


Figure 1

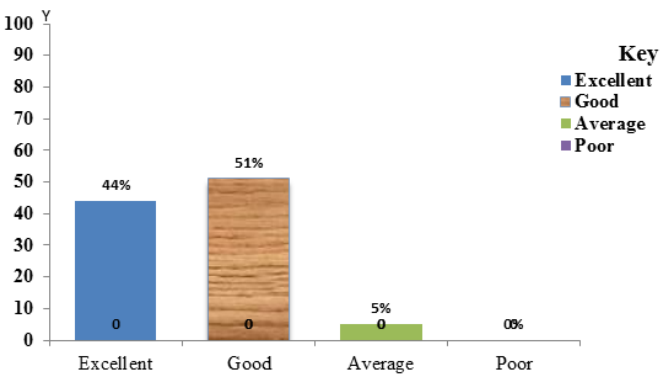

\section{REFERENCES}

1. Ramsay DB, Friedman M, Borum ML. Does the race or gender of hepatitis C infected patients influence physicians' assessment of hepatitis $A$ and hepatitis B serologic status? South Med J. 2007; 100:683-5.

2. Malik AH, Lee WM. Chronic hepatitis B virus infection: Treatment strategies for the next millennium. Ann Intern Med. 2000;132:723-31.

3. Tandon BN, Acharya SK, Tandon A. Epidemiology of hepatitis B virus infection in India. Gut. 1996;38(Suppl 2):S56-9.

4. Batham A, Narula D, Toteja T, Sreenivas V, Puliyel JM. Sytematic review and meta-analysis of prevalence of hepatitis B in India. Indian Pediatr. 2007:44:663-74

5. Jha J, Banerjee K, Arankalle VA. A high prevalence of antibodies to hepatitis C virus among commercial plasma donors from Western India. J Viral Hepat. 1995;2:257-60.

6. Nandi J, Bhawalkar V, Mody H, Elavia A, Desai PK, Baneriee K. Detection of HIV-1, HBV and HCV antibodies in blood donors from Surat, western India. Vox Sang. 1994;67:406-7.

7. Polish LB, Tong MJ, Co RL, Coleman PJ, Alter MJ. Risk factors for hepatitis C virus infection among health care personnel in a community hospital. Am J Infect Control. 1993;21:196-200.

8. Kermode M, Holmes W, Langkham B, Thomas MS, Gifford S. HIV-related knowledge, attitudes and risk perception amongst nurses, doctors and other healthcare workers in rural India. Indian J Med Res. 2005; 122:258-64.

9. Nagao Y, Matsuoka H, Kawaguchi T, Ide T, Sata M. HBV and HCV infection in Japanese dental care workers. Int J Mol Med. 2008;21:791-9.

10. Askarian $M$, Yadollahi $M$, Kuochak $F$ Danaei M, Vakili V, Momeni M. Precautions for health care workers to avoid hepatitis $B$ and $C$ virus infection. Int J Occup Environ Med. 2011;2:191-8.

11. Razi A, Rehman R, Naz S, Ghafoor F, Ullah MA. Knowledge attitude and practices of university students regarding hepatitis B and C. ARPN J Agric Biol Sci. 2010;5:38-43.

12. Shiao J, Guo L, Mclaws ML. Estimation of the risk of blood borne pathogens to health care workers after a needle stick injury in Taiwan. Am J Infect Control 2002;30:15-20

13. Lokesh U, Srinidhi D, Reddy KS. Post exposure prophylaxis to occupational injuries for general dentist. J Indian Prosthodont Soc 2014;14:1-3

14. Noubiap JJN, Nansseu JRN, Kengne KK, Ndoula ST, Agyingi LA. Occupational exposure to blood, hepatitis B vaccine knowledge and uptake among medical students in Cameroon. BMC Med Edu 2013;13:148

15. Ibrahim N, Idris A. Hepatitis B awareness among medical students and their vaccination status at Syrian Private University. Hepat Res Treat 2014;Article ID 131920

16. Shaheen S, Nighat N, Majid HQ. Knowledge regarding hepatitis B among EPI vaccinators working in district sout, Karachi. Pak J Med Sci. 2007;23:538-41.

17. Samuel SO, Aderibigbe SA, Salami T, Babatunde OA. Health workers' knowledge, attitude and behaviour towards hepatitis B infection in Southern Nigeria. Int J Med Sci. 2009; 1:418-24.

18. Paudel DP, Prajapati SK, Paneru DP. Hepatitis B related knowledge and perception of nursing students: an institutional based study in Kathmandu, Nepal. Int J Health Sci Res 2012;2:57-66 